\title{
Functional MRI in Macaque Monkeys during Task Switching
}

\author{
(E) Elsie Premereur, ${ }^{1,2}$ (Peter Janssen, ${ }^{1,2}$ and ${ }^{\circ W}$ Wim Vanduffel ${ }^{1,2,3,4}$ \\ ${ }^{1}$ Lab. voor Neuro- \& Psychofysiologie, KU Leuven, Leuven, Belgium, ${ }^{2}$ Leuven Brain Institute, Leuven, Belgium, ${ }^{3}$ Athinoula A. Martinos Center for \\ Biomedical Imaging, Massachusetts General Hospital, Charlestown, MA, and ${ }^{4}$ Department of Radiology, Harvard Medical School, Massachusetts, MA
}

Nonhuman primates have proven to be a valuable animal model for exploring neuronal mechanisms of cognitive control. One important aspect of executive control is the ability to switch from one task to another, and task-switching paradigms have often been used in human volunteers to uncover the underlying neuronal processes. To date, however, no study has investigated task-switching paradigms in nonhuman primates during functional magnetic resonance imaging (fMRI). We trained two rhesus macaques to switch between arm movement, eye movement, and passive fixation tasks during fMRI. Similar to results obtained in human volunteers, task switching elicits increased fMRI activations in prefrontal cortex, anterior cingulate cortex, orbitofrontal cortex, and caudate nucleus. Our results indicate that the macaque monkey is a reliable model with which to investigate higher-order cognitive functioning such as task switching. As such, these results can pave the way for a detailed investigation of the neural basis of complex human behavior.

Key words: cognitive control; executive control; fMRI; macaque; task-switch

\section{Significance Statement}

Task switching is an important aspect of cognitive control, and task-switching paradigms have often been used to investigate higher-order executive functioning in human volunteers. We used a task-switching paradigm in the nonhuman primate during fMRI and found increased activation mainly in prefrontal areas $(46,45$, frontal eye field, and anterior cingulate), in orbitofrontal area 12 , and in the caudate nucleus. These data fit surprisingly well with previous human imaging data, proving that the monkey is an excellent model to study task switching with high spatiotemporal resolution tools that are currently not applicable in humans. As such, our results pave the way for a detailed interrogation of regions performing similar executive functions in humans and monkeys.

\section{Introduction}

The ability to switch voluntarily from one task to another is central to intelligent behavior, as it allows an organism to flexibly adapt to ever-changing external conditions and internal needs. Switching at will from one cognitive task to another is also fundamental to executive control. It is precisely for this reason that task-switching paradigms have been used as reliable operational measures of executive functions. As such, a large body of psychological research has focused upon this behavior in human sub-

\footnotetext{
Received June 18, 2018; revised Aug. 27, 2018; accepted 0ct. 15, 2018.

Author contributions: E.P., P.J., and W.V. designed research; E.P. performed research; E.P. and W.V. analyzed data; E.P., P.J., and W.V. wrote the paper.

This work was supported by the Research Foundation Flanders (FWO Grants G0007.12, G0A5613N, and GOB8617N); the Financing Program of the KU Leuven (Grants PFV/10/008 and C14/17/109); European Union's Horizon 2020 Framework Programme for Research and Innovation under Grant Agreement 785907 (Human Brain Project SGA2); and the Hercules Foundation. We thank Anne Coeman, Stijn Verstraeten, Piet Kayenbergh, Gerrit Meulemans, Marc De Paep, and Inez Puttemans for assistance. We also thank Steve Raiguel for comments on a previous version of this manuscript.

The authors declare no competing financial interests.

Correspondence should be addressed to Wim Vanduffel, KU Leuven, Laboratorium voor Neuro en Psychofysiologie, 0\&N II Herestraat 49, Bus 1021, 3000 Leuven, Belgium, E-mail: wim@nmr.mgh.harvard.edu. https://doi.org/10.1523/JNEUROSCI.1539-18.2018

Copyright $\odot 2018$ the authors $\quad 0270-6474 / 18 / 3810619-12 \$ 15.00 / 0$
}

jects (Sohn and Anderson, 2001; Yeung and Monsell, 2003a,b). These studies have implicated prefrontal cortex (PFC) and anterior cingulate cortex (ACC) as primary substrates for task-switching signals (Miller and Cohen, 2001; Rushworth et al., 2002; Wylie et al., 2004; Liston et al., 2006; Woodward et al., 2006). Both areas are strongly interconnected (Bates and Goldman-Rakic, 1993; Paus et al., 2001; Wang et al., 2004), suggesting that they may be involved in similar cognitive functions. This was confirmed by functional neuroimaging studies showing a strikingly similar recruitment of PFC and ACC in a multitude of cognitive tasks, including response conflict, task novelty, working memory, episodic memory, task switching, and problem solving (Duncan, 2010). The specific functional contributions of both of these areas to task switching, however, remain unclear.

More detailed information about the exact timings of single neurons in PFC and ACC and their causal role in task switching can be obtained only by using animal models. In a recent study, Caselli and Chelazzi (2011) have shown that the nonhuman primate is an adequate model for task-switching behavior. Previous research found neurons in macaque superior colliculus to be implicated in task switching (Chan et al., 2017). Lesion studies in orbitofrontal and ventrolateral prefrontal cortex found these lat- 
ter areas to be involved in reversal learning (Rudebeck et al., 2013, 2017). Moreover, an electrophysiological study in the monkey showed the recruitment of ACC when cognitive demands increase and suggested a role for both ACC and PFC in task maintenance and top-down control (Johnston et al., 2007). Furthermore, lesion and inactivation studies in monkeys have demonstrated impairments in task switching following both PFC (Dias et al., 1996) and ACC (Shima and Tanji, 1998; Rushworth et al., 2003) lesions. Imaging studies using resting-state paradigms found increased functional connectivity between ACC and PFC (Hutchison et al., 2012; Goulas et al., 2017). To the best of our knowledge, however, no study has yet investigated the cortical areas involved in task switching using fMRI in awake nonhuman primates. There has been a single report of fMRI results evoked during set shifting but not task switching (Nakahara et al., 2002). To fill this void, we performed an fMRI study to identify the cortical and subcortical areas of the macaque implicated in task switching. To this end, rhesus monkeys were trained to switch dynamically between different types of operant behavior (fixation, eye movements, or arm movements), which were cued by different colors. We found increased fMRI activations related to task switching in relatively restricted sectors of the cortex, including the frontal eye field (FEF), prefrontal areas $45 \mathrm{~b}$ and $46 \mathrm{v}$, orbitofrontal area 12 , the anterior cingulate cortex, and also subcortically in the caudate nucleus.

\section{Materials and Methods}

All experimental procedures were performed in accordance with the $\mathrm{Na}$ tional Institute of Health Guide for the Care and Use of Laboratory Animals and EU Directive 2010/63/EU, and were approved by the Ethical Committee at KU Leuven. The animals in this study were pair or group housed with cage enrichment (toys, foraging devices) at the primate facility of the KU Leuven Medical School. They were fed daily with standard primate chow supplemented with nuts, raisins, prunes, and fresh fruits.

\section{Surgery}

All experiments were performed using three male rhesus monkeys (Macaca mulatta): juvenile monkey R (4 kg), adult monkey $\mathrm{U}(5.8 \mathrm{~kg})$, and adult money $\mathrm{K}(6 \mathrm{~kg})$. Two monkeys ( $\mathrm{U}$ and $\mathrm{R})$ were used in the main experiment and one $(\mathrm{K})$ in a control experiment. After training to sit in a primate chair, a custom-made head post was implanted on the skull using ceramic screws and dental acrylic. At least 6 weeks after surgery, the monkeys began training in passive fixation and eye and/or arm movement tasks.

\section{Training}

Monkeys were trained in a mock fMRI setup. They were seated in a sphinx position in a plastic monkey chair directly facing an LCD screen (viewing distance, $57 \mathrm{~cm}$; Vanduffel et al., 2001). Eye position was monitored at $120 \mathrm{~Hz}$ using pupil position (Iscan).

\section{Tasks}

In the main experiment, three types of tasks were presented to the animals in blocks: a passive fixation task (Fix), a visually guided eye movement task (Eye), and a visually guided arm movement task (Arm; Fig. $1 A)$. Monkey $\mathrm{R}$ was first trained in the eye movement task, followed by training in the arm movement task, while the reverse was true for monkey U. All tasks were described in detail previously (Premereur et al., 2015a).

Visually guided eye movement task. The animal had to maintain fixation within a $2^{\circ} \times 2^{\circ}$ window around a small red fixation point in the center of a black display for a fixed period of $200 \mathrm{~ms}$, after which a green target appeared. After a variable delay (between 500 and $2000 \mathrm{~ms}$ ), a "go" cue indicated to the animal to make an eye movement toward the green target (Fig. 1B). The animal was rewarded for an eye movement toward the target. To prevent the animals from learning the exact timing of the go signal, the time between target onset and the go signal was a semirandom variable.

The following two types of go signals were used: in the single-cue task, the dimming of the central fixation point served as the go signal; while in the multiple-cue task, four gray distractors appeared simultaneously with the target, and the dimming of one of them (randomly chosen) would serve as the go signal.

Throughout the trials, the subject had to keep both hands in the rest position on a plastic bar located in front of the animal. The positions of both hands were monitored using infrared laser beams.

Visually guided arm movement task. During the Arm task, a blue target appeared in exactly the same configuration as during the eye movement task. The color of the target (blue, rather than green) indicated to the monkey to maintain fixation in the center of the screen and to respond to the go signal by moving the hand ipsilateral to the target. When the go cue appeared, the animal had to briefly retract the ipsilateral hand while maintaining the contralateral hand in the start position. The positions of both hands were continuously monitored using the infrared laser beams. Stimulus, timing and go-cue parameters (except for the color of the target) were identical to those used in the visually guided eye movement task.

Fixation task. In the fixation task, five gray distractors were used. The absence of a green or blue target, together with the lack of a go signal, indicated to the animal to maintain fixation until the end of the trial. The subject had to keep his hands in the rest position.

Control experiments. To control for any interference from training in the eye movement task upon the arm movement task, we performed a separate fMRI experiment (control experiment 1 ; monkey U) with only the Arm and Fix task, before the animal had been trained on the visually guided eye movement task.

For similar purposes, one additional animal (monkey K), naive to the Arm task, was trained to switch between a visually guided eye movement task and a fixation task (control experiment 2). During the eye movement task, which was slightly different from that of the main experiment, a green target appeared randomly in one of the four quadrants. The animal had to maintain fixation until the central fixation point dimmed, which served as the go signal to make an eye movement toward the peripheral target. During the fixation task, the animal had to maintain fixation while one peripheral dot (having the same size and color as the target in the eye movement task) appeared at one of four positions, corresponding to the target locations used in the eye movement task of the main experiment. The color of the fixation point indicated to the animal whether he should make an eye movement or hold fixation.

\section{Scanning}

The tasks [Eye, Arm, and Fix in the main experiment (Fig. 1A); Arm and Fix in control experiment 1; and Eye and Fix in control experiment 2] were presented to the animals in multiple blocks within an fMRI run (monkey R: 120 runs; one run = 205 functional volumes; two Fix blocks/ run, four Arm blocks, four Sacc blocks; monkey U: 121 runs; one run = 285 functional volumes; six Fix blocks/run, four Arm blocks, four Sacc blocks; monkey K: 121 runs; one run $=245$ functional volumes; eight Fix blocks/run, four Sacc blocks). Twenty functional volumes were acquired during each $40 \mathrm{~s}$ block. Note that, although the tasks were presented in a block design, data were analyzed in an event-related fashion, only including results from the volume corresponding to the trial of interest.

Functional images were acquired with a $3.0 \mathrm{~T}$ full-body scanner (Tim Trio Scanner, Siemens), using a gradient-echo $\mathrm{T} 2{ }^{*}$-weighted echoplanar imaging (EPI) sequence (40 horizontal slices; TR, 2 s; TE, 16 ms; 1.25 $\mathrm{mm}^{3}$ isotropic voxels) with a custom-built eight-channel phased-array receive coil; and a saddle-shaped, radial transmit-only surface coil (Kolster et al., 2009). Before each scanning session, a contrast agent, monocrystalline iron oxide nanoparticle (MION; Sinerem, Laboratoire Guerbet), was injected into the femoral/saphenous vein $(7-11 \mathrm{mg} / \mathrm{kg})$.

\section{Image preprocessing}

An off-line image reconstruction was conducted to overcome problems inherent to monkey body motion in a $3 \mathrm{~T}$ magnetic field. Details of the image reconstruction protocol have been described previously (Kolster 

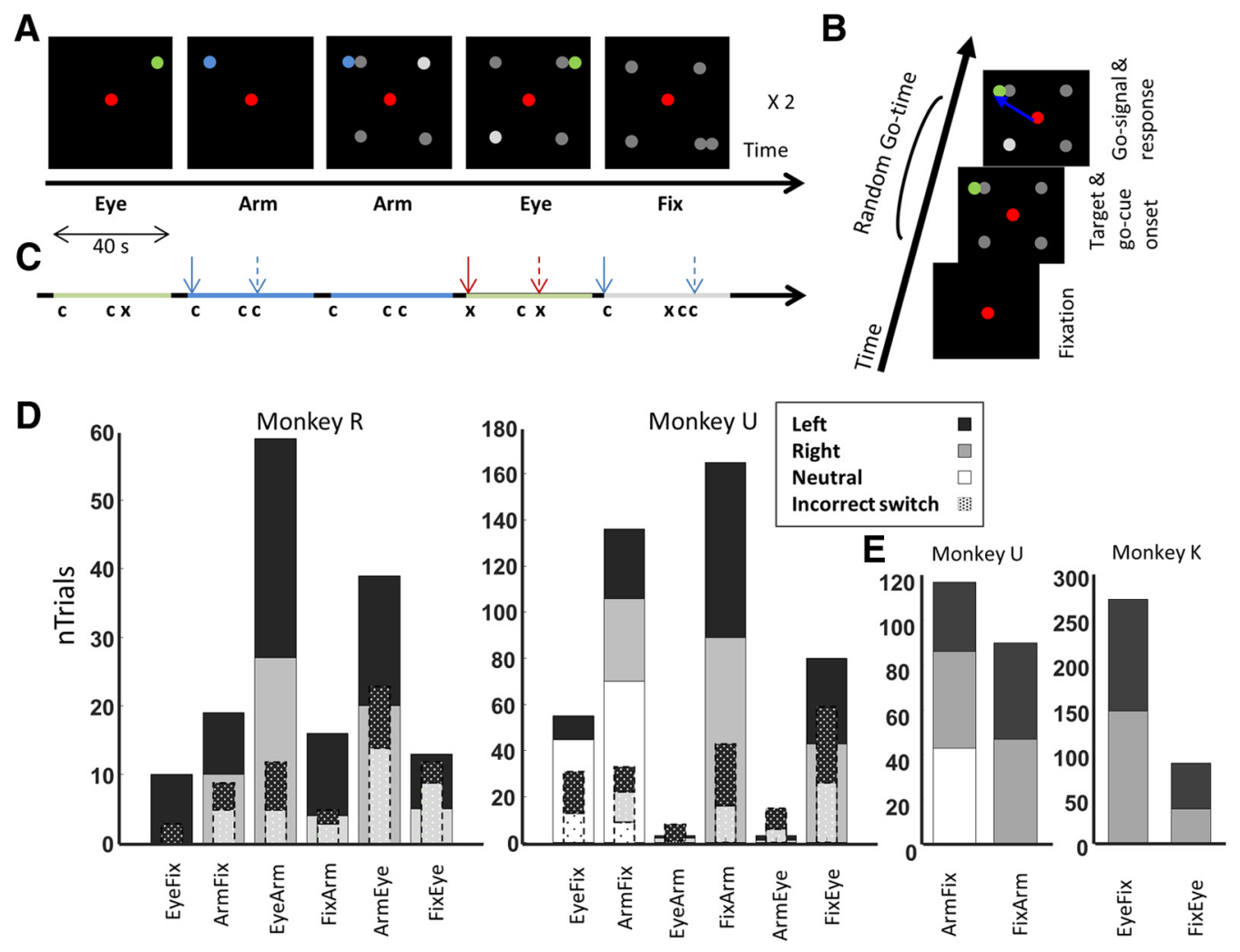

Figure 1. Methods and behavior. $A$, The animals were presented with 40 s blocks of an Eye (green target), Arm (blue target), or Fix (gray distractor) task. Operant behavior tasks were presented as single-cue (left and middle left) or multiple-cue (middle and right middle) tasks. $\boldsymbol{B}$, After a fixation period, target and go cues appear on the screen. The dimming of one of the possible gray go cues served as the go signal for the multiple-cue tasks, while the dimming of the red fixation point served as the go cue for the single-cue tasks. Animals had to make an eye movement toward the green target or move the hand ipsilateral to the blue target. Fixation had to be maintained in the absence of a blue or green target. $C$, Types of events. Solid blue arrows indicate correct (c) switches between operant behavior; dashed blue arrows indicate correct stay trials (following another correctly executed trial) randomly selected from the same block as the switch trial; red arrows indicate incorrect $(\mathrm{x})$ switch trials; dashed red arrows indicate incorrect stay trials $(\mathrm{x})$ randomly selected from the same block as the incorrect switch trial. $\boldsymbol{D}$, Total number of switch trials in all runs. Switch trials are divided per type of switch (e.g. Eyefix: switch from Eye to Fix). The bar color indicates the direction of the operant behavior in the switch trial (dark gray, left; light gray, right). White indicates a neutral condition, in which the animal was presented with only the central fixation point (no direction indication; only for monkey U). Smaller dotted bars with dashed outlines show the number of incorrect switch trials. $\boldsymbol{E}$, Total number of trials in control experiments. Left, Monkey U, switching between Arm and Fix. Right, Monkey K, switching between Eye and Fix.

et al., 2009). Briefly, the raw EPI images were corrected for lowest-order off-resonance effects and aligned with respect to the gradient-recalledecho reference images before performing a SENSE (sensitivity encoding) image reconstruction. Corrections for higher-order distortions were performed using a nonrigid, slice-by-slice distortion correction.

\section{Event-related analysis}

A white square $\left(0.29^{\circ}\right)$ was superimposed on the first video frame containing a stimulus (target and go cues in Eye and Arm, or peripheral dots in Fix) appearing in the lower right corner of the otherwise black screen. This square was completely obscured from the view of the monkeys but was detected by a fiber-optic cable transferring the signal to a photodiode. The onset of the white square, digitized and processed at $20 \mathrm{kHz}$ on a digital signal processor (C6000 series, Texas Instruments), provided the time stamp used to extract the exact timing of every event in each trial.

Correct switch trials were defined as the first trial of a block in which the behavioral response was different from the response in the previous block (Fig. 1C). A stay trial was defined as the first correctly performed trial from the second half of the block, which was preceded by another correctly performed (stay) trial. For every block in which a correct switch trial was found, a stay trial was also included in our analysis, thus obtaining the same number of switch and stay trials (Fig. 1C).

Finally, incorrectly performed switch trials were defined as the first (incorrectly performed) trial of a block in which the behavioral response was different from the response in the previous block. To avoid including short, incorrect switch trials (e.g., by fixation abort), we included only incorrect switch trials that were not followed by correct switch trials in the first $2 \mathrm{~s}$ after the task switch. To have an exact match (in terms of operant behavior) for every incorrect switch trial, we included an incorrectly performed stay trial from every block starting with an incorrect switch trial (same procedure as for the stay trials described above). Only incorrectly performed stay trials of $>1500 \mathrm{~ms}$ were included.

To investigate the effect of operant behavior, individual Arm and Eye trials were also included in the analysis. Correct Arm or Eye trials were included in the analysis, randomly chosen to equalize the number of trials to the number of correct switch trials. T values were calculated for the contrasts Arm movement versus Fixation and Eye movement versus Fixation.

\section{Experimental design and statistical analysis}

Experimental design. The tasks [Eye, Arm, and Fix in the main experiment (Fig. 1A); Arm and Fix in control experiment 1 and Eye and Fix in control experiment 2] were presented to the animals in multiple blocks within an fMRI run. Twenty functional volumes were acquired during each $40 \mathrm{~s}$ block, and each block was repeated twice in one run.

Volume-based data analysis. Data were analyzed in an event-related fashion using statistical parametric mapping (SPM5-12; RRID:SCR_007037) and BrainMatch software, based on a fixed-effects general linear model (GLM). Realignment parameters were included as covariates of no interest to remove motion artifacts. The rate and amount of rewards were also included as a covariate of no interest. Each condition was modeled by convolving a gamma function (delta $=0$, tau $=8$, and exponent $=0.3$ ), modeling the MION hemodynamic response function, at the onset of every trial over a period of $2 \mathrm{~s}$, reflecting the average length of a trial (Premereur et al., 2015a). 
Spatial preprocessing consisted of realignment and rigid coregistration with a template anatomy (M12; Ekstrom et al., 2008). The functional images were warped to the template anatomy using nonrigid matching BrainMatch Software (Chef d'Hotel et al., 2002). Regularization of the deformation field was obtained by low-pass filtering. The functional volumes were resliced to $1 \mathrm{~mm}^{3}$ isotropic and smoothed with an isotropic Gaussian kernel (full-width at half-maximum, $1.5 \mathrm{~mm}$ ). To identify those voxels that were more activated for any given contrast in both subjects, a conjunction analysis of the main experiment was performed between the two animals, in which we identified all voxels significantly activated in both animals at a level of $p<0.001$, uncorrected for multiple comparisons. Note that only a randomly selected but restricted number of runs for monkey $\mathrm{U}$ was included in the conjunction analysis to equalize the number of runs for both animals.

Regions of interest. For region of interest (ROI)-based analysis, we functionally defined nonoverlapping $3 \times 3 \times 3 \mathrm{~mm}$ boxes around the hotspots of the activations (local maxima as determined by SPM5) resulting from the conjunction analysis between the two animals (contrast switch correct vs stay). Note that the latter conjunction analysis was performed on half of the data (including 17 runs for monkey R and 18 for monkey U) to avoid circularity. The other half of the data was used to extract the percentage of signal change (PSC).

ROI-based analysis. All ROI analyses were performed using MarsBaR version 0.41.1 (RRID:SCR_009605). To calculate significant differences in the PSC between conditions, two-tailed paired $t$ tests were performed and, if necessary, significance values were corrected for multiple comparisons (Bonferroni's correction).

Multivoxel pattern analysis. The PRONTO toolbox (version 2.0; RRID: SCR_006908; Schrouff et al., 2013) was used to perform all multivoxel pattern analyses (MVPAs) using an SVM (support vector machine) classifier. Beta weights obtained from the GLM analysis as described above were used as inputs to overcome problems inherent to a fast event-related design regarding the slow hemodynamic response function. The leaveone-block-out cross-validation type was used, and permutation tests were performed to determine statistical significance of classification accuracy.

Statistical analysis. To assess significant differences in PSC between conditions or between condition and baseline, paired $t$ tests were performed. Significance levels were Bonferroni corrected for multiple comparisons.

\section{Results}

Two rhesus monkeys were trained to switch among three different tasks in blocks, each involving another type of operant behavior: Arm, Eye, or Fix; Fig. 1A,B; Premereur et al., 2015a). The color of the target (blue, green, or gray) indicated the type of operant, and the tasks were presented to the animals in a pseudorandom order. To investigate the effect of task switching on neural activations, we compared the fMRI signal at the time of correct switch trials to the signal at the time of (correctly performed) stay trials, in which the animal had to perform the same operant behavior as in the preceding trial (Fig. 1C).

We collected data from 121 and 120 runs for monkeys $U$ and $\mathrm{R}$, respectively. Only runs with at least 2 correct switch and stay trials were included in the analysis, leaving 111 and 35 runs for monkeys $U$ and $\mathrm{R}$, respectively (comprising, respectively, 442 and 156 correct switch and stay trials; Fig. 1D). Note that one stay trial was selected for every correct switch trial. Furthermore, we obtained 64 and 192 incorrect switch trials for monkeys R and U, respectively.

Figure $1 D$ shows the number of correct and incorrect switch trials, differentiating between switch types. As the animals had to switch between three different types of behavior, we defined six types of switch trials, as follows: Eye followed by Fix (EyeFix); Arm followed by Fix (ArmFix); Eye followed by Arm (EyeArm); Fix followed by Arm (FixArm); Arm followed by Eye (ArmEye); and Fix followed by Eye (FixEye). The target or distractor in the switch trial could be presented on either the left side (black bars) or right side (gray bars) of the screen, indicating the side of the operant behavior for Arm and Eye conditions. Furthermore, for monkey $\mathrm{U}$, we included a fixation condition without distractors, indicating to the animal to fixate centrally (neutral condition, white bars). Figure $1 D$ shows the number of trials for every type of switch and distinguishes between the two directions of operant behavior in the switch trials (left or right). We found a substantial difference in the number of correct switch trials, depending on the experimental design (note that the original goal of the study was to investigate neural activity during different types of operant behavior). Monkey U was not regularly presented with EyeArm trials $\left(n_{\text {Correct }}=3\right.$ trials $)$ and ArmEye trials $\left(n_{\text {Correct }}=3\right.$ trials $)$, but rather switched between Arm or Eye and Fix (and vice versa). The reverse was true for monkey $\mathrm{R}$, from which we included more EyeArm and ArmEye trials. Note that neither animal displayed a clear preference for leftward- or rightward-oriented operant behavior in the correct switch trials (Fig. 1D, compare black bars, gray bars; monkey U: right, 156 of 442 trials, 35\%; left, 171 of 442 trials, 39\%; neutral, 115 of 442 trials, 26\%; monkey R: left, 66 of 156 trials, $42 \%$; right, 90 of 156 trials, 58\%). Similar trends were noted for incorrect switch trials (dotted bars; monkey R: left, 36 of 64 trials, 56\%; right, 28 of 64 trials, 44\%; monkey U: left, 63 of 192 trials, 33\%; right, 105 of 192 trials, 54\%; neutral, 24 of 192 trials, $13 \%)$. Note that we included only one-third of the data for monkey $\mathrm{U}$ in the conjunction analysis presented below, to equalize the number of runs between the two animals (number of runs included in conjunction analysis: monkey R, 35; monkey $\mathrm{U}, 36$; number of correct switch trials: monkey U, 141; monkey R, 156). We included a qualitatively similar distribution of trial types in the analyses, with the majority of switch trials being of the type ArmFix (44 of 141 trials) or FixArm (53 of 141 trials), and no clear differentiation between switch trials to the left $(n=54)$ or right $(n=55)$. Figure $1 E$ displays the performance of the animals during the control experiments. In a first control experiment, monkey U had to switch between Arm and Fix blocks. A total of 117 ArmFix trials were included in our analysis (distractor in the left hemifield, 31 of 117 trials; distractor in the right hemifield, 43 of 117 trials; no distractor, 43 of 117 trials), and 90 FixArm trials (target in the left hemifield, 43 of 90 trials; target in the right hemifield, 47 of 90 trials). In a second control experiment, monkey K had to switch between Sacc and Fix blocks. A total of 273 EyeFix trials were included in our analysis (distractor in the left hemifield, 125 of 273 trials; distractor in the right hemifield, 148 of 273 trials), and 90 FixEye trials (target in the left hemifield, 51 of 90 trials; target in the right hemifield, 39 of 90 trials).

To identify cortical areas involved in task switching, we contrasted the fMRI activity during correct switch trials with stay trials (contrast: correct switch vs stay trial). Figure $2 A$ shows all areas significantly more activated during correct switch compared with stay trials, for the two subjects individually (note that all runs are included in the results presented in Fig. 2A). For both animals, we found activations related to task switching in highly similar (sub)cortical areas: switching to another type of operant behavior increased activations bilaterally in prefrontal areas 45b, $\mathrm{FEF}$, and 46v; in orbitofrontal area 12; in anterior cingulate cortex (area 24); and in the subcortical caudate nucleus $(p<0.05$, FWE corrected). Furthermore, for both animals, we obtained increased activations along the superior temporal sulcus [areas PIT (posterior inferior temporal cortex), MT (middle temporal area), and AIT (anterior inferior temporal cortex)] and in visual area V4. Finally, we found restricted parietal activations related to task 
A

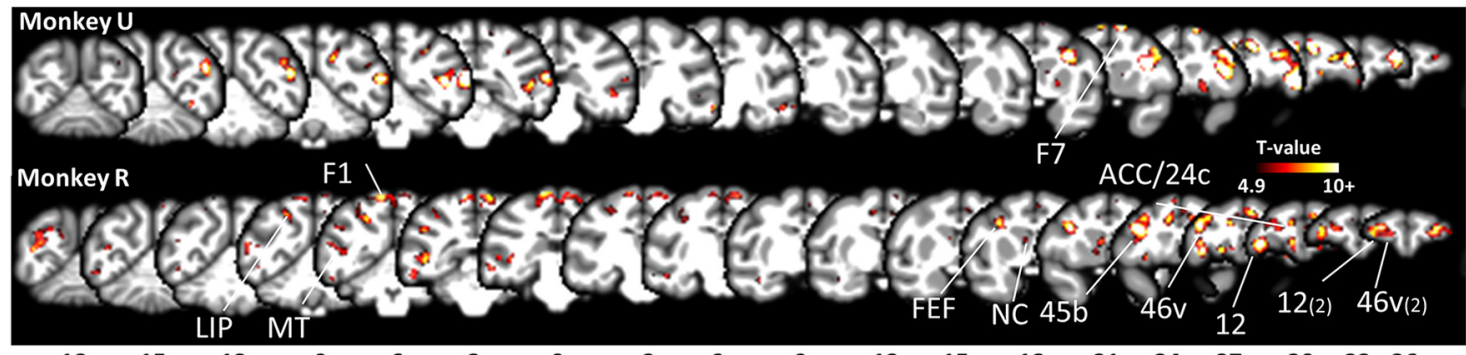

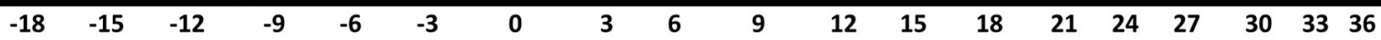

B

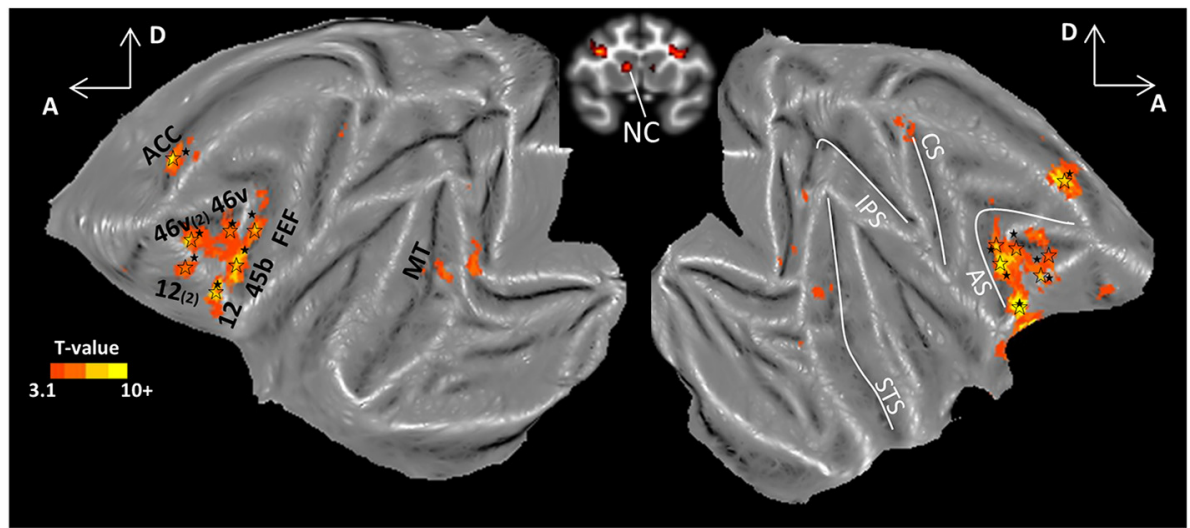

C

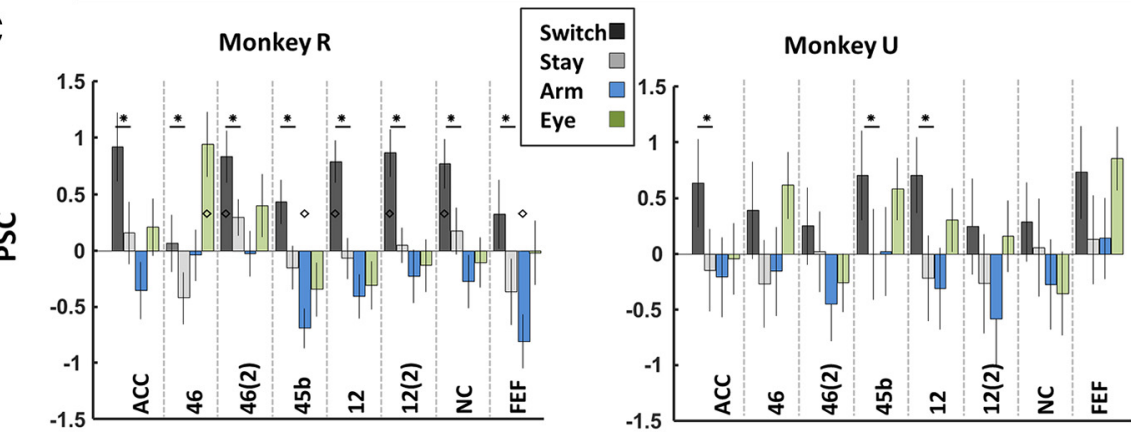

Figure 2. Correct switch trials vs stay trials. $A, t$ Score maps on $M 12$ anatomical template for the contrast correct switch vs stay for monkey $U$ (top row) and $\mathrm{R}$ (bottom row). $p<0.05$, FWE corrected. Bottom numbers indicate anteroposterior coordinates. Hotspots (as defined by the conjunction analysis in $\boldsymbol{B}$ ) are indicated. Cortical areas with two hotspots are labeled as 12 (2) and $46 \mathrm{v}$ (2). $\boldsymbol{B}, t$ Score map for the conjunction analysis between the two animals, shown on the M12 flat map ( $p<0.001$ uncorrected). Star outlines indicate activation hotspots, and small black stars indicate hotspots as determined from half of the data. AS, Arcuate sulcus; CS, central sulcus; IPS, intraparietal sulcus; STS, superior temporal sulcus; D, dorsal; A, anterior. C, PSC for the hotspots indicated with the small black stars in $\boldsymbol{A}$, representing the hotspots based on half of the data. PSC is calculated on the other half of the dataset (split-half analysis). Black asterisk indicates a significant difference between correct switch and stay (paired $t$ test, $p<0.05$, corrected for multiple comparisons). Diamonds indicate a significant difference from baseline (paired $t$ test, $p<0.05$, corrected for multiple comparisons). Baseline is the Fix condition.

switching located in the lateral intraparietal sulcus. These activations were, however, lateralized and were obtained in the right hemisphere for monkey $U$ and in the left hemisphere for monkey R (Fig. 2A). The latter cannot be explained by a greater number of switch trials toward the left or right (Fig. 1D). Note that we also obtained increased fMRI activation in area F7 (Supplementary Eye Fields; SEF) for monkey U, and in F1 for monkey R.

The overlapping switch-related activations present in both animals became evident in a conjunction analysis (including all 35 runs for monkey R and 36 randomly selected runs for monkey $\mathrm{U} ; p<0.001$, uncorrected; Fig. 2B). Indeed, in both animals switching to another type of operant behavior induces activations mainly in prefrontal and orbitofrontal areas 45b, FEF, 46v, 12, anterior cingulate cortex, and, to a lesser extent, in area MT. The conjunction analysis also shows a significant activation for task switching in the caudate nucleus (NC, Fig. 2B, inset). Throughout the remainder of the manuscript, we will focus on the prefrontal areas, as indicated by the stars in Figure $2 B$. These stars indicate the hotspots among these activations, and are located in the above-described areas 45b, 12 (two hotspots), 46v (two hotspots), FEF, and ACC.

To calculate the PSC in these prefrontal areas, we performed a conjunction analysis on half of the data (including 17 runs for monkey R and 18 runs for monkey $\mathrm{U}$ ). We first determined the hotspots of the activations for the latter analysis (Fig. $2 B$, filled stars) and defined nonoverlapping $3 \times 3 \times 3 \mathrm{~mm}$ ROIs around these hotspots. We next calculated the PSC in the remaining half of the runs (18 runs for both animals) to avoid circularity. Note that the locations of the hotspots of the activations are very similar to the full dataset (Fig. 2B, compare open stars, smaller filled stars). Figure $2 C$ shows significantly higher PSCs during correct switch trials compared with stay trials for all ROIs in monkey $\mathrm{R}$ [45b, FEF, 46v (both hotspots), 12 (both hotspots), and ACC], and for ACC, 45b, and 12 in monkey $\mathrm{U}$ (paired $t$ tests; $p<0.05$, Bonferroni corrected for multiple comparisons, indicated with black asterisks). Note that the PSC typically did not differ from 
A
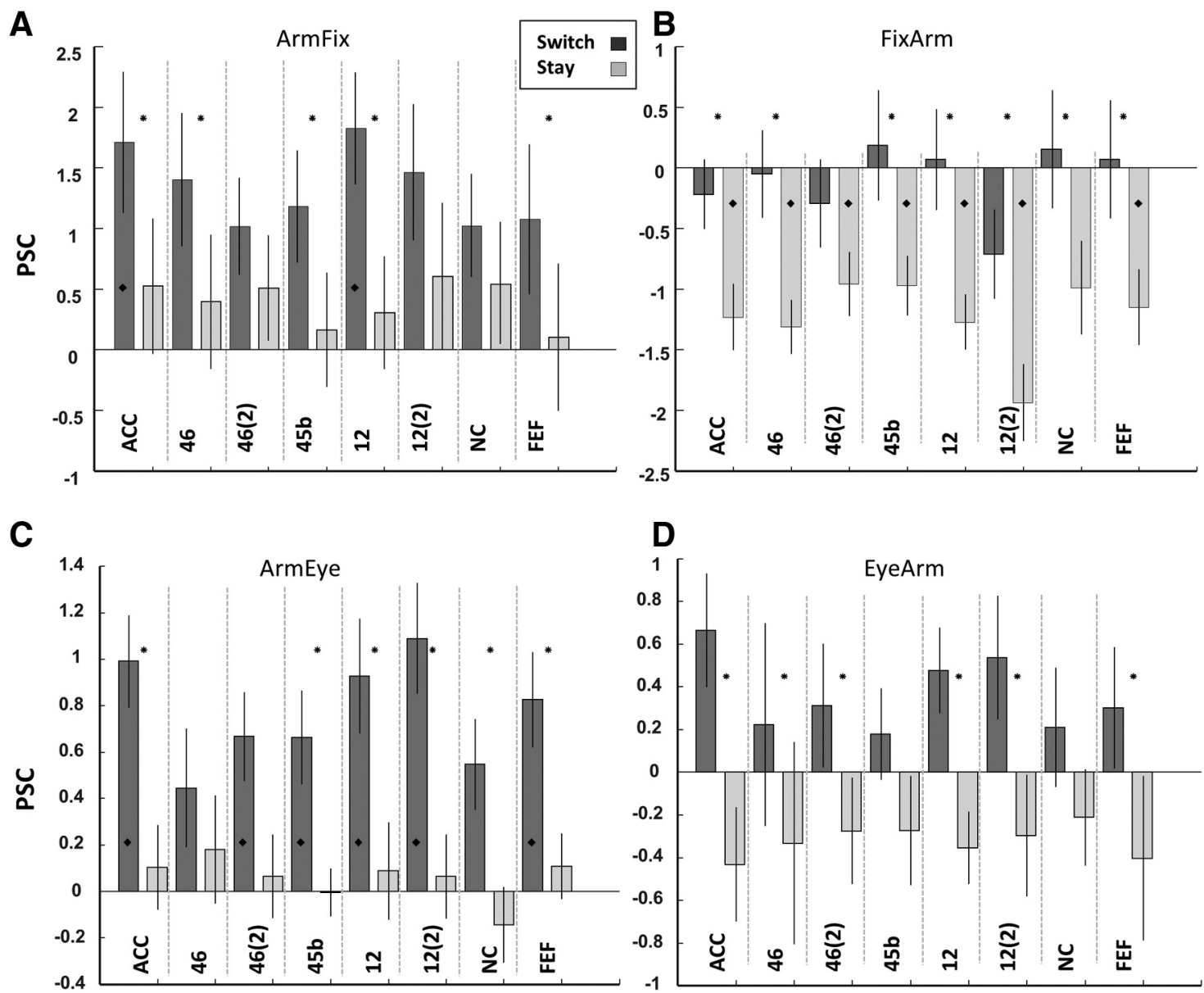

Figure 3. PSC during one type of switch. A, Monkey U, switch from Arm block to Fix block. B, Monkey U, switch from Fix block to Arm block. C, Monkey R, switch from Arm to Eye block. $D$, Monkey $R$, switch from Eye to Arm block. Black lines indicate the SEM. Black asterisks indicate a significant difference between switch and stay trials (paired $t$ tests, $p<0.05$, Bonferroni corrected for multiple comparisons). Black diamonds indicate a significant difference from baseline (paired $t$ tests, $p<0.05$, Bonferroni corrected for multiple comparisons). Baseline is the Fix condition.

baseline for stay trials in monkey $\mathrm{R}$, and for both stay and correct switch trials in monkey $U$ (paired $t$ tests; $p<0.05$, Bonferroni corrected for multiple comparisons, indicated with black diamonds). The differences between conditions were less pronounced for monkey $U$ compared with monkey R. A significant difference between correct switch and stay trials was, however, found for all ROIs when the analysis was based on the hotspots defined over all runs, or for the ROIs (except the second hotspot in 46v) described here when all runs were included (paired $t$ tests, $p<0.05$, Bonferroni corrected for multiple comparisons). Note that the response patterns in the majority of ROIs are similar except for FEF. Indeed, Figure 2C shows a decreased PSC in FEF during Arm in monkey R, which is not present for monkey $\mathrm{U}$. Monkey $\mathrm{U}$, on the contrary, shows increased FEF activity during eye movements, which is not present in monkey R. Note that monkey $\mathrm{R}$ has been trained to do the eye-movement task before receiving training in the arm-movement task, while the reverse was true for monkey U. The different response patterns in FEF, an area that has been implicated in attention and eye movements, may be explained by the different training history and the acquired response strategies.

As shown in Figure $1 D$, various types of switch trials were included in our analysis. The relative contributions of these switch types differed between animals, as described above. Despite such individual differences, results were highly similar in the two subjects, suggesting that the results shown in Figure 2 do not depend on the type of switch. To further investigate the effect of switch type on the results, we distinguished between FixArm and ArmFix trials from monkey $U$ (the subject having the largest dataset), and repeated the GLM analysis including only one of these switch types. Figure 3 shows the PSC calculated in the same ROIs as described above (Fig. $2 B$, filled stars). For both switch types, we found an increased PSC for correct switch versus stay trials (Fig. 3A-B, black asterisks) for the majority of ROIs [ACC, 46v, 45b, 12, FEF for ArmFix; ACC, 46v, 45b, 12 (including both hotspots), and FEF for FixArm], although the overall response patterns for switch and stay trials differed substantially [threeway ANOVA with factors ROI, trial type (switch-stay), and switch type (FixArm-ArmFix): $F_{\mathrm{ROI}}=0.25, \mathrm{df}=7, p=0.97$; $F_{\text {trialtype }}=37.25, \mathrm{df}=1, p<0.001 ; F_{\text {switchtype }}=113.45, \mathrm{df}=1$, $p<0.001]$. Note that we obtained a decreased PSC for stay trials when switching from Fix to Arm, which is in line with the findings in the study by Premereur et al. (2015a). Similar results were obtained for monkey R, by comparing the difference between switching from Eye to Arm versus switching from Arm to Eye [Fig. 3C,D; three-way ANOVA with factors ROI, trial type (switch-stay), and switch type (EyeArm-ArmEye): $F_{\mathrm{ROI}}=0.78$, $\mathrm{df}=7, p=0.61 ; F_{\text {trialtype }}=21.13, \mathrm{df}=1, p<0.001 ; F_{\text {switchtype }}=$ 71.89, $\mathrm{df}=1, p<0.001]$. 

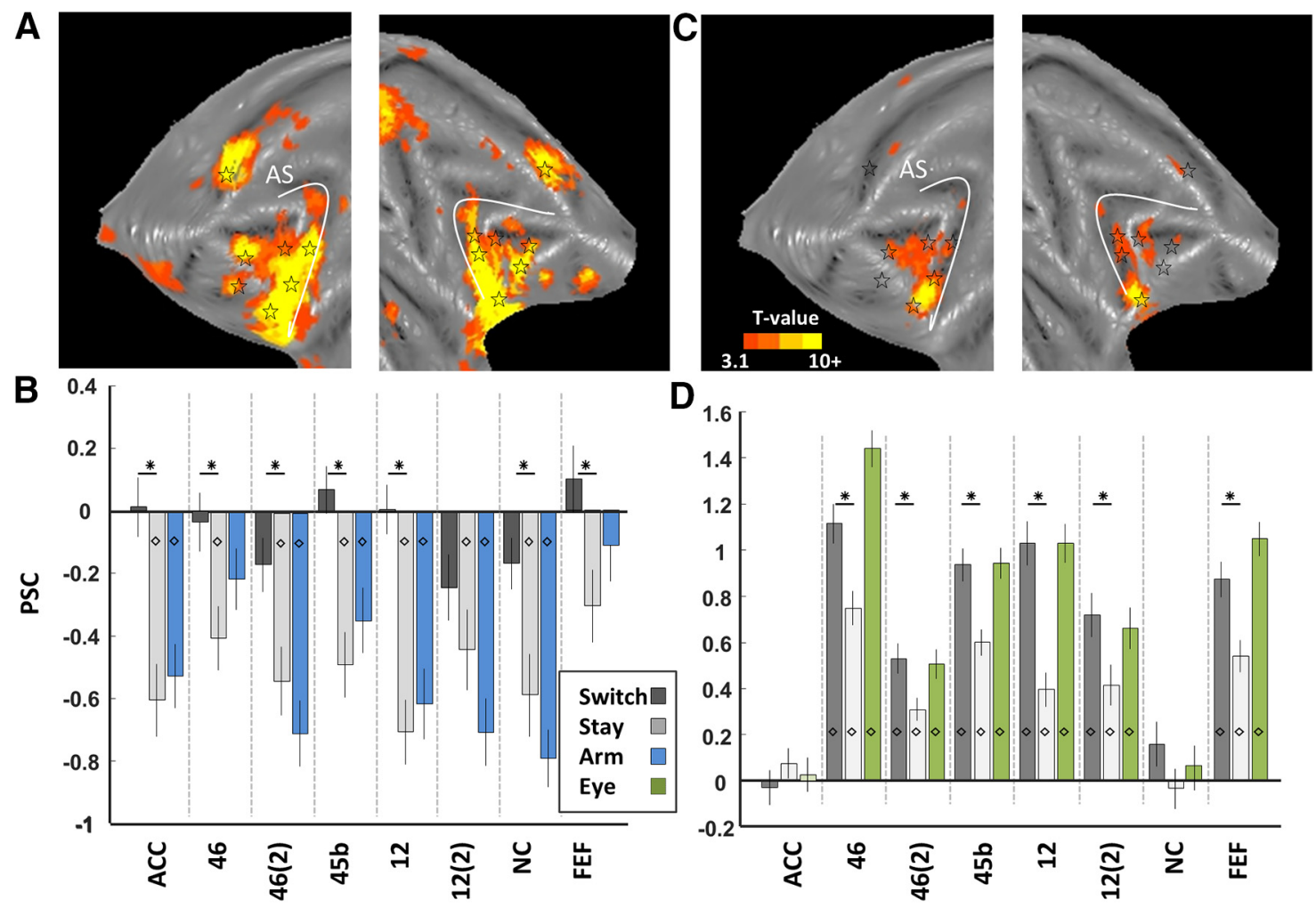

Figure 4. Control experiments. $A$, Switch vs stay trials during alternation between Arm and Fix trials (monkey U). $t$ Score map shown on an M12 flat map ( $p<0.001$ ). Stars indicate hotspots, as in Figure 2B. AS, Arcuate sulcus. B, PSC during alternation between Arm and Fix trials (monkey U). Asterisk indicates a significant difference between correct switch and stay trials (paired $t$ tests, $p<$ $\mathbf{0 . 0 5}$, corrected for multiple comparisons). Diamonds indicate significant differences from baseline (paired $t$ tests, $p<0.05$, corrected for multiple comparisons). $\boldsymbol{C}$, Switch vs stay trials during alternation between Eye and Fix trials (monkey K). D, PSC during alternation between Eye and Fix trials (monkey K).

The lack of any task effect was further confirmed in a control experiment in which monkey $U$ was only switching between arm movements and fixation (and vice versa; Fig. $4 A$; note that at this point, the animal had never been trained in an eye movement task). Switching between Arm and Fix blocks increased activation in the same frontal areas as switching among Fix, Arm, and Eye trials did. These areas included prefrontal and orbitofrontal areas $45 \mathrm{~b}, \mathrm{FEF}, 46 \mathrm{v}, 12$, and anterior cingulate cortex. For ease of comparison, the stars indicate the activation hotspots as in Figure 2B. A significant difference in PSC between correct switch and stay trials (using the same ROIs as in Fig. 2C) was found for all ROIs except the second hotspot in area 12 [12(2); Fig. 4B]. The significantly lower PSC during stay trials compared with the fixation baseline (Fig. $4 B$, gray bars, significance indicated with black diamonds) was due to the decreased PSC during Arm trials compared with baseline (Fig. 4B, blue bars; Premereur et al., 2015a). The similarity of task switching between Arm and Fix trials and Arm, Eye, and Fix trials was further confirmed by a strong correlation (0.65) between the $t$ values of both contrasts (Pearson correlation on $t$ values obtained for all brain voxels). Note that we also found similar activations for the contrast correct switch versus stay outside the prefrontal and orbitofrontal cortex, namely in areas FST (fundus of the superior temporal sulcus), LIP (lateral intraparietal area), and V4 (data not shown).

In the previously described design, the operant behavior tasks (Arm or Eye) could be either a single- or multiple-cue task (Fig. $1 A$ ), thus differing in visual input and attentional conditions. However, even when the same visual configuration was used and similar attentional demands were required during the different types of operant behaviors (Eye and Fix in this case, thus differing only in the color of the fixation point indicating the type of op- erant behavior; note that switches could occur in both directions: EyeFix or FixEye), a similar network of frontal areas was activated during switch versus stay trials, although the fMRI activations were typically lower [Fig. 4C; control monkey K, stars indicate the hotspots (as in Fig. 2B); Pearson correlation $=0.32$, calculated on all brain voxels using $t$ values from the current (correct switch vs stay) contrast with the contrast (correct switch vs stay) from the conjunction analysis, as shown in Fig. 2B]. As with the results of the main experiment (Fig. $2 C$ ), Figure $4 D$ indicates a significantly higher PSC for correct switch trials compared with stay trials for all ROIs [45b, FEF, 12 (both hotspots), and 46v (both hotspots)] except for caudate nucleus and ACC (ROIs as determined by split-half procedure; Fig. $2 B, C$ ). However, the lack of effect in $\mathrm{ACC}$ is due to the slight shift of the activations: Figure $4 \mathrm{C}$ nonetheless shows higher activity during correct switch trials compared with stay trials in ACC just outside the hotspot as defined in Figure $2 B$.

So far, only correct switch trials (vs correct stay trials) have been discussed. Do incorrectly executed switch trials evoke similar activations compared with correct switch trials? To test this possibility, we included incorrect switch and stay trials in our design (Fig. $1 D$, number of trials). Our results indicate a similar response pattern during incorrectly executed switch trials (vs stay trials; number of incorrect switch trials: monkey R, 64; monkey $\mathrm{U}, 68)$ compared with correctly executed switch trials [vs stay trials; compare Fig. $2 B$, Fig. $5 A$; conjunction analysis for monkeys $\mathrm{U}$ and $\mathrm{R}$ for the contrast (incorrect switch vs stay), $p<0.001$, uncorrected]. Figure 5, $B$ and $C$, shows the PSC calculated in the ROIs described above during correct switch trials (and their matching stay trials) and incorrect switch trials (and their matching stay trials; matched in terms of the operant behavior and 

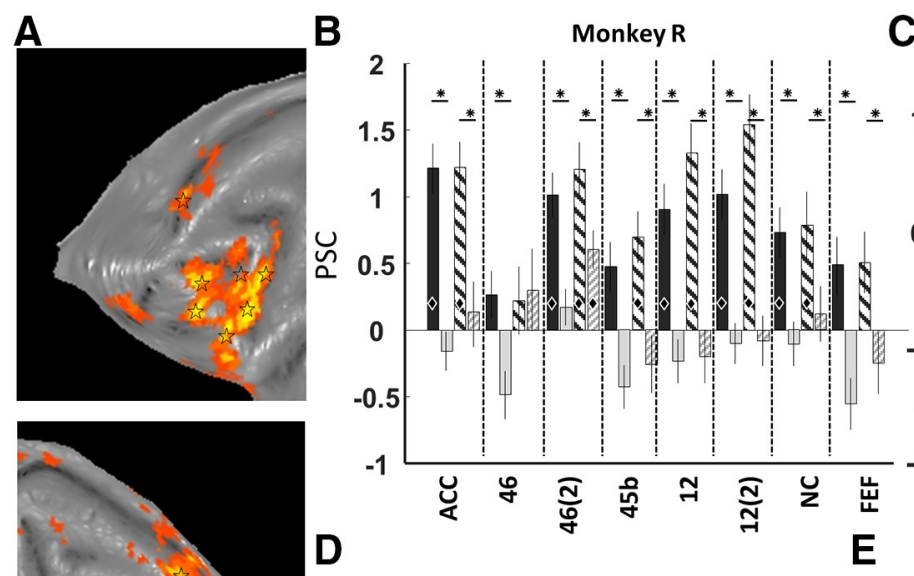

C MonkeyU
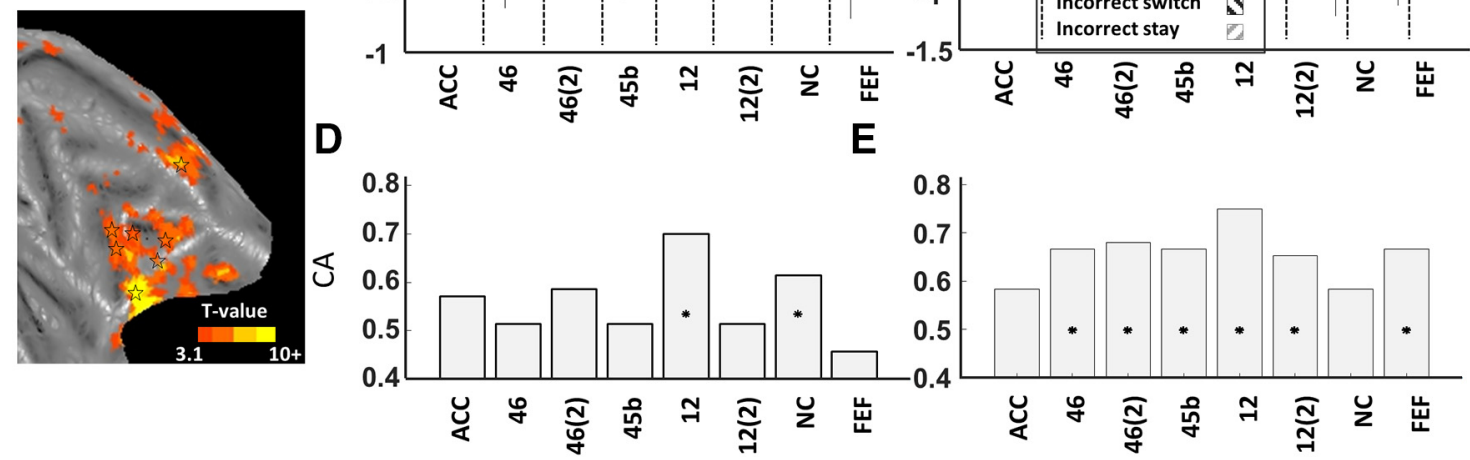

Figure 5. Incorrect switch trials. $\boldsymbol{A}$, Contrast incorrect switch vs stay. A $t$ score map for the conjunction analysis between both animals, shown on an M12 flat map ( $p<0.001$, uncorrected). Stars indicate activation hotspots from contrast correct switch vs stay, as in Figure 2B. B, PSC in ROls as defined in Figure 2. Monkey R. C, Monkey U. Stars indicate a significant difference between (in)correct switch trials and matching stay trials. Diamonds indicate a significant difference from baseline (paired $t$ tests, $p<0.05$, Bonferroni corrected for multiple comparisons). Vertical black lines indicate SEM. D, MVPA classification accuracy (CA) for monkey R. E, Monkey U. Asterisks indicate significant classification accuracy (permutation test, $p<0.05$ ).

being incorrectly executed). As with results described above, we found significant differences in activity between switch and stay trials for both animals (ANOVA with factors ROIs, switch type (switch vs stay), and answer (incorrect vs correct): $p_{\text {switchtype }}<$ 0.001 for both monkeys). Individual ROIs displayed a significant difference between correct switch and stay trials (except caudate nucleus in monkey U; Figure $5 B, C$, compare black and gray bars; post hoc $t$ tests, $p<0.05$, Bonferroni corrected for multiple comparisons) and between incorrect switch and stay trials (except area 46 in monkey R: Figure $5 B, C$, compare black and gray striped bars; post hoc $t$ tests, $p<0.05$, corrected for multiple comparisons). More importantly, we obtained a significant difference in activation during incorrectly versus correctly performed trials [ANOVA with factors ROI, switch type (switch vs stay), and answer (incorrect vs correct): $p_{\text {answer }}<0.001$ for both monkeys]. A significant difference between PSC during incorrectly versus correctly executed trials can be indicative of error signaling. Incorrectly versus correctly executed switch trials evoked higher activity in all the ROIs of monkey $\mathrm{U}$ [except for area $46 \mathrm{v}$ (second hotspot) and the caudate nucleus; Figure $5 B, C$, compare black and striped black bars], while this held true for none of the ROIs in monkey $\mathrm{R}$ (paired $t$ tests, $p<0.05$, Bonferroni corrected for multiple comparisons). Finally, no significant differences were found between the correctly executed and incorrectly executed stay trials (except caudate nucleus and area 12 (second hotspot) in monkey U; Figure $5 B, C$, compare gray and striped gray bars, post hoc $t$ tests, $p>0.05$, corrected for multiple comparisons).

To further investigate potential differences between neural activation patterns evoked by correct and incorrect switches, we used an MVPA on the voxels of the same ROIs described above. The classification results were in line with the PSC profiles displayed in Figure 5, $B$ and $C$ : for monkey R, we found reliable classification only between incorrect and correct switch trials in area 12 and the caudate nucleus. For monkey U, all ROIs (except ACC and the caudate nucleus) reliably classified both types of switch trials (Fig. $5 D, E$ ). Note that the difference between these two animals cannot be explained by a different number of events included in the analysis (Fig. 1D).

Prefrontal areas are also involved in spatial attention and eye movements (Schall et al., 1995; Koyama et al., 2004; Baker et al., 2006), two cognitive operations with highly similar neural representations (Rizzolatti et al., 1987; Nobre et al., 2000; Corbetta and Shulman, 2002; Wardak et al., 2011). As explained above, the switch-related activations described here were not due merely to the eye movement task, as the same regions were activated during task switches not relying on saccades. We compared the neural activity during task switching (based on correct switches) and eye movements. We obtained only minimal overlap between the saccade-related activations (Fig. 6A, contrast Eye movement vs. Fixation, white outlines in Figure $6 A, p<0.05$, FWE corrected) and the task-switch activations (contrast correct switch vs stay; Fig. 6A, color-coded voxels) for monkey R. Partially overlapping activations were limited to the upper bank of the arcuate sulcus corresponding to areas FEF and $45 \mathrm{~B}$ for monkey $\mathrm{U}$ (Pearson correlation between $t$ values of all brain voxels for contrast eye movement vs fixation and contrast correct switch vs stay; monkey R, 0.24; monkey U, 0.19). Furthermore, MVPAs indicated clearly different neural patterns for task switching than for eye movements, with all ROIs (except ACC for monkey $\mathrm{U}$ ) reliably classifying both events correctly (Fig. $6 B$; permutation test, $p<0.05$ ).

\section{Discussion}

Our study directly compared fMRI activations in the macaque brain during switching between operant behaviors, using an ex- 

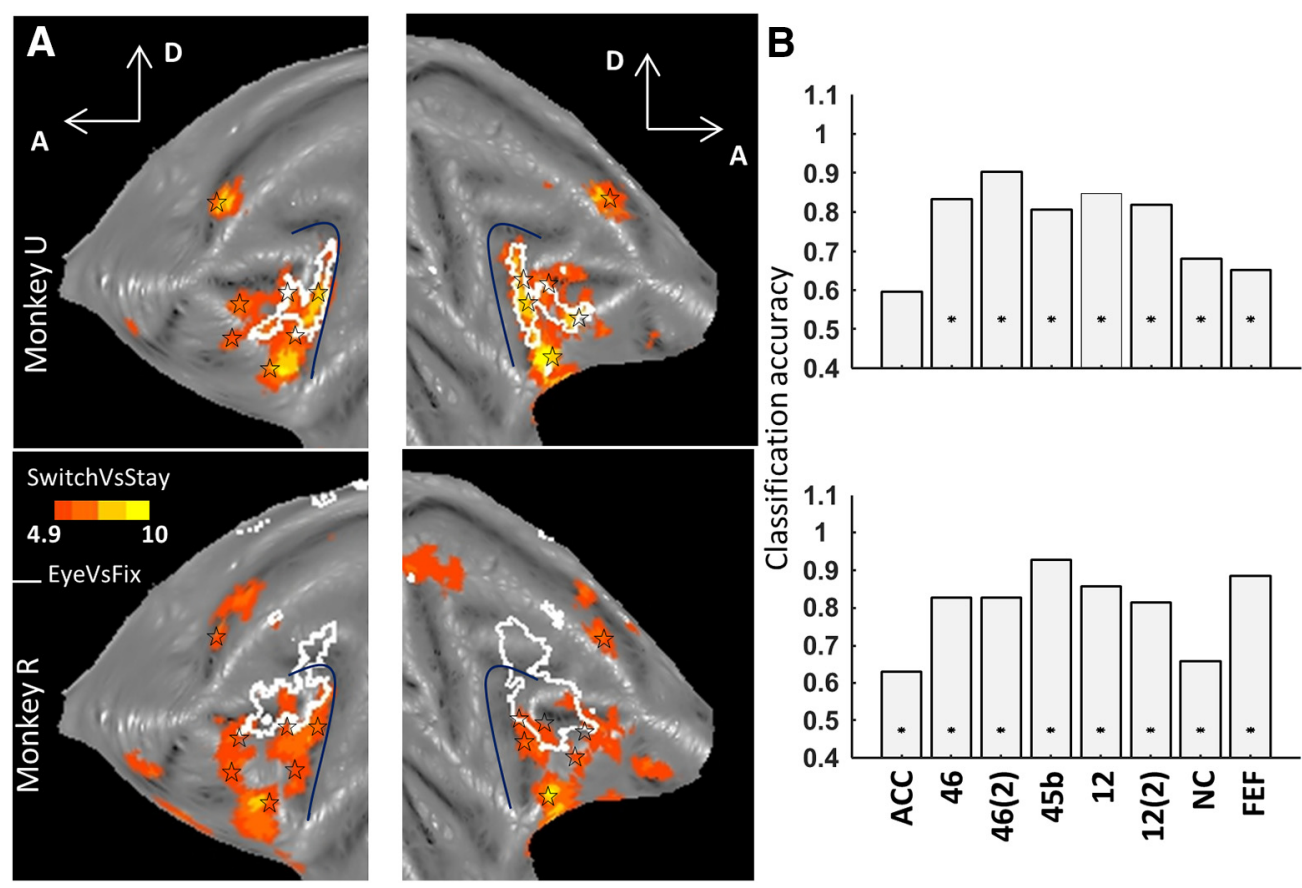

Figure 6. Comparison of the eye movement-related network to the task-switch network. $A$, Contrast correct switch vs stay ( $p<0.05$, FWE corrected) shown on an M12 template for both monkeys individually. White outlines display results for contrast Eye vs Fix ( $p<0.05$, FWE corrected). Top, monkey U. Bottom, monkey R. Stars indicate hotspots as in Figure $2 B$. $\boldsymbol{B}$, MVPA results for the classification of saccade trials vs switch trials. Asterisks indicate significant classification accuracies (permutation test, $p<0.05$ ).

ternal cue. We showed that areas activated during task switching are located mainly in prefrontal, orbitofrontal, and anterior cingulate cortex, similar to results previously obtained in human volunteers. Our results indicate that the macaque monkey is a valuable model for investigating task switching, thereby providing a way forward for more detailed electrophysiological and causal experiments.

The ability to switch from one task to another requires highlevel cognitive functions at the core of executive control, a hallmark of intelligent behavior. An animal model expressing such functions would be an invaluable tool for investigating the neural basis of complex human behavior. (Caselli and Chelazzi, 2011) have previously compared task-switching costs in human and nonhuman primates. In contrast to a previous study (Stoet and Snyder, 2003), the authors found robust task-switching costs for both species. Hence, macaque monkeys provide an exquisite model to study the brain mechanisms responsible for maintaining and switching among task sets. Note that the presence of a fixation task in our design did not allow us to investigate taskswitching costs in terms of altered reaction times. The use of monkeys as a model for task switching can provide crucial information concerning single-unit and causal mechanisms of cognitive flexibility (Johnston et al., 2007; Kamigaki et al., 2009; Pouget et al., 2011).

Several fMRI studies using healthy human volunteers have investigated task switching using designs similar to that of the current study (Dove et al., 2000; Kimberg et al., 2000; Sohn et al., 2000; Monsell, 2003). Typically, these have revealed numerous (sub)cortical areas showing activations related to task switching (for review, see Monsell, 2003), including areas located in the medial and lateral regions of human prefrontal cortex and anterior cingulate cortex, but also in regions within the parietal lobes and cerebellum, SMA/pre-SMA, and anterior insula (Dove et al., 2000; Wylie et al., 2004; Crone et al., 2006; Liston et al., 2006; Woodward et al., 2006).
Both task switching and set shifting require cognitive flexibility, and these terms are often used as synonyms. Set shifting, as investigated by the Wisconsin card sorting task, probes the ability to shift from one response tendency (cognitive set) based on previous experiences, to another more suited to the current circumstances. Typically, subjects are not aware of the shifted rule. Task switching, as used in the current context, refers to a sudden change in operant behavior following an alteration in external circumstances (e.g., the color of the target). To the best of our knowledge, no study has investigated task switching using fMRI in nonhuman primates. Lesion and inactivation studies in monkeys have demonstrated impairments in task switching following both PFC (Dias et al., 1996) and ACC lesions (Shima and Tanji, 1998; Rushworth et al., 2003). A study comparing fMRI activations in humans and macaques during set shifting (using the Wisconsin card sorting task) found similar activations in prefrontal cortex for both species, located in cytoarchitectonically equivalent regions in the posterior part of ventrolateral PFC corresponding to areas 45b, 46, and 12 (Nakahara et al., 2002). The similarities between humans and monkeys during set shifting indicate common neural mechanisms underlying set shifting and provide insights into the evolution of cognition in humans. While the present results also provide evolutionary insight into another high-level cognitive skill, task switching, prior investigations, in contrast, have found no increased activation in ACC but rather in posterior cingulate cortex (PCC), a node of the default mode network (Raichle et al., 2001; Hayden et al., 2009). Previous research indicated that neurons in PCC decreased their firing rates during task switching (Hayden et al., 2010), possibly explaining the lack of activation during task switching in our own study. Note, however, that we observed no PCC deactivation during task switching.

Previous research has detected increased fMRI activations in macaque V6/V6a during shifts in spatial attention (Caspari et al., $2015,2018)$. Although shifts in spatial attention are not uncom- 
mon in task-switching designs, our study did not show increased V6/V6a activation during task switching. This is most likely due to our task design, in which the animals had to continually shift spatial attention to the target, and in the multiple-cue version of the task, also to the go cue (i.e., the dimming of one of the gray distractors presented on the screen). Thus, similar spatial attention shifts occurred in the switch and stay trials, which may have obscured finding generalized switching-related activations within V6/V6A.

To investigate the neuronal underpinnings of task switching, we compared event-related activations between trials differing only by the preceding trial type (different or same). Switch and stay trials, however, most likely also trigger a variety of (cognitive) processes, beyond mere task switching (Monsell, 2003). Switch trials, for example, may elicit changes in general arousal or more pronounced error-monitoring mechanisms compared with stay trials. The increased activity during incorrectly performed trials in the current experiment could be indicative of increased error monitoring. Furthermore, differential activations evoked by stimuli on switch and stay trials do not differentiate between the "source" and the "target" of the cognitive control. By combining fMRI (with high spatial resolution) and extracranial event related potentials (with high temporal resolution), Brass et al. (2005) found that PFC precedes parietal cortex during task switching. Likewise, Johnston et al. (2007) investigated singleunit responses of ACC and PFC during task switching and found that neural activity in the ACC leads to activity in the PFC following a task switch.

Currently, only a limited number of studies have investigated the causal role of PFC in task switching. A study of patients with unilateral PFC lesions demonstrated that damage centered over the right ventrolateral PFC (VLPFC) correlated better with switch costs in a task-switching paradigm (Aron et al., 2004b). Furthermore, reversible inactivation of human medial frontal cortex with transcranial magnetic stimulation (TMS) indicated a crucial role for pre-SMA in task switching (Rushworth et al., 2002). Lesion and inactivation studies in monkeys have demonstrated impairments in task switching following both PFC (Dias et al., 1996) and ACC (Shima and Tanji, 1998; Rushworth et al., 2003) lesions. The results obtained from fMRI experiments in nonhuman primates may pave the way for more detailed causal investigations of task switching by using reversible manipulations such as chemical inactivation (Van Dromme et al., 2016), electrical microstimulation (Premereur et al., 2015b), optogenetics (Vanduffel et al., 2014), or TMS (Rushworth et al., 2002) to better clarify the causal role of the area under study.

Dorsolateral PFC, VLPFC, and dorsal ACC have been implicated in several high-level cognitive operations (Duncan and Owen, 2000) and were found to be part of a multiple-demand system of the brain (together with parietal areas; Duncan, 2010). Traditionally, a major role attributed to the PFC was that of response inhibition, a cognitive process required to cancel an intended movement. A recent overview described the ventrolateral PFC (comprising Brodmann areas 44, 45, and 47/12) as mostly concerned with inhibition, a mechanism by which it exerts control over subcortical and parietal areas (Aron et al., 2004a). Switching from one task to another indeed requires inhibition of the previously performed response, and a direct neuroimaging comparison of rule switching (Wisconsin card sorting task) and response inhibition demonstrated a common locus in the right VLPFC in humans (Konishi et al., 1999).
Our current study could only partially differentiate between incorrect and correct switch trials. This might be due to the low temporal resolution of fMRI, as the animals would typically make a correct switch trial within $\sim 5 \mathrm{~s}$ after the first task-switching trial. Furthermore, trials can be performed incorrectly for a variety of reasons (incorrect operant behavior, too fast or too slow responses, etc.), which are difficult to distinguish within the current design. Alternatively, the same cognitive processes could be present during both correct and incorrect switch trials (increased arousal, error monitoring, response inhibition). The conflictmonitoring hypothesis (Botvinick et al., 2001) has been proposed to account for the relative influences of different brain areas in the implementation of cognitive control, and suggested a role for ACC in conflict monitoring and error detection (Carter et al., 2000). However, similar to our results, previous electrophysiology studies did not find any increase in ACC response during incorrectly performed trials (Johnston et al., 2007; but see also Ito et al., 2003; Nakamura et al., 2005). More detailed experiments such as fMRI-guided electrophysiological recordings will be necessary to disentangle the various cognitive processes evoked during task switching.

Cells in the ventral prearcuate gyrus have been implicated in feature-based attention, in contrast to neurons in the ventral bank of the principal sulcus (Bichot et al., 2015) and neurons in FEF (implicated in spatial attention (Moore and Armstrong, 2003; Juan et al., 2004; Wardak et al., 2006). In the current study, we obtained increased activation of area $45 \mathrm{~b}$ in the ventral bank of the principal sulcus. As described above, the latter could be due to response inhibition or, alternatively, that the subjects were cued for the type of operant behavior by means of a different target color, leading to increased activation in area $45 \mathrm{~b}$ during task switching due to heightened feature-based attention to target color in task switch conditions.

\section{References}

Aron AR, Robbins TW, Poldrack RA (2004a) Inhibition and the right inferior frontal cortex. Trends Cogn Sci 8:170-177. CrossRef Medline

Aron AR, Monsell S, Sahakian BJ, Robbins TW (2004b) A componential analysis of task-switching deficits associated with lesions of left and right frontal cortex. Brain 127:1561-1573. CrossRef Medline

Baker JT, Patel GH, Corbetta M, Snyder LH (2006) Distribution of activity across the monkey cerebral cortical surface, thalamus and midbrain during rapid, visually guided saccades. Cereb Cortex 16:447-459. CrossRef Medline

Bates JF, Goldman-Rakic PS (1993) Prefrontal connections of medial motor areas in the rhesus monkey. J Comp Neurol 336:211-228. CrossRef Medline

Bichot NP, Heard MT, DeGennaro EM, Desimone R (2015) A source for feature-based attention in the prefrontal cortex. Neuron 88:832-844. CrossRef Medline

Botvinick MM, Braver TS, Barch DM, Carter CS, Cohen JD (2001) Conflict monitoring and cognitive control. Psychol Rev 108:624-652. CrossRef Medline

Brass M, Ullsperger M, Knoesche TR, von Cramon DY, Phillips NA (2005) Who comes first? The role of the prefrontal and parietal cortex in cognitive control. J Cogn Neurosci 17:1367-1375. CrossRef Medline

Carter CS, Macdonald AM, Botvinick M, Ross LL, Stenger VA, Noll D, Cohen JD (2000) Parsing executive processes: strategic vs. evaluative functions of the anterior cingulate cortex. Proc Natl Acad Sci U S A 97:1944-1948. CrossRef Medline

Caselli L, Chelazzi L (2011) Does the macaque monkey provide a good model for studying human executive control? A comparative behavioral study of task switching. PLoS One 6:e21489. CrossRef Medline

Caspari N, Janssens T, Mantini D, Vandenberghe R, Vanduffel W (2015) Covert shifts of spatial attention in the macaque monkey. J Neurosci 35:7695-7714. CrossRef Medline

Caspari N, Arsenault JT, Vandenberghe R, Vanduffel W (2018) Functional 
similarity of medial superior parietal areas for shift-selective attention signals in humans and monkeys. Cereb Cortex 28:2085-2099. CrossRef Medline

Chan JL, Koval MJ, Johnston K, Everling S (2017) Neural correlates for task switching in the macaque superior colliculus. J Neurophysiol 118:21562170. CrossRef Medline

Chef d'Hotel C, Weiger M, Scheidegger MB, Boesiger P (2002) Flows of diffeomorphisms for multimodal image registration. Proc IEEE Int Symp Biomed Imaging 7:753-756.

Corbetta M, Shulman GL (2002) Control of goal-directed and stimulusdriven attention in the brain. Nat Rev Neurosci 3:201-215. CrossRef Medline

Crone EA, Wendelken C, Donohue SE, Bunge SA (2006) Neural evidence for dissociable components of task-switching. Cereb Cortex 16:475-486. CrossRef Medline

Dias R, Robbins TW, Roberts AC (1996) Primate analogue of the wisconsin card sorting test: effects of excitotoxic lesions of the prefrontal cortex in the marmoset. Behav Neurosci 110:872-886. CrossRef Medline

Dove A, Pollmann S, Schubert T, Wiggins CJ, von Cramon DY (2000) Prefrontal cortex activation in task switching: an event-related fMRI study. Brain Res Cogn Brain Res 9:103-109. CrossRef Medline

Duncan J (2010) The multiple-demand (MD) system of the primate brain: mental programs for intelligent behaviour. Trends Cogn Sci 14:172-179. CrossRef Medline

Duncan J, Owen AM (2000) Common regions of the human frontal lobe recruited by diverse cognitive demands. Trends Neurosci 23:475-483. CrossRef Medline

Ekstrom LB, Roelfsema PR, Arsenault JT, Bonmassar G, Vanduffel W (2008) Bottom-up dependent gating of frontal signals in early visual cortex. Science 321:414-417. CrossRef Medline

Goulas A, Stiers P, Hutchison RM, Everling S, Petrides M, Margulies DS (2017) Intrinsic functional architecture of the macaque dorsal and ventral lateral frontal cortex. J Neurophysiol 117:1084-1099. CrossRef Medline

Hayden BY, Smith DV, Platt ML (2009) Electrophysiological correlates of default-mode processing in macaque posterior cingulate cortex. Proc Natl Acad Sci U S A 106:5948-5953. CrossRef Medline

Hayden BY, Smith DV, Platt ML (2010) Cognitive control signals in posterior cingulate cortex. Front Hum Neurosci 4:223. CrossRef Medline

Hutchison RM, Gallivan JP, Culham JC, Gati JS, Menon RS, Everling S (2012) Functional connectivity of the frontal eye fields in humans and macaque monkeys investigated with resting-state fMRI. J Neurophysiol 107:2463-2474. CrossRef Medline

Ito S, Stuphorn V, Brown JW, Schall JD (2003) Performance monitoring by the anterior cingulate cortex during saccade countermanding. Science 302:120-122. CrossRef Medline

Johnston K, Levin HM, Koval MJ, Everling S (2007) Top-down controlsignal dynamics in anterior cingulate and prefrontal cortex neurons following task switching. Neuron 53:453-462. CrossRef Medline

Juan CH, Shorter-Jacobi SM, Schall JD (2004) Dissociation of spatial attention and saccade preparation. Proc Natl Acad Sci U S A 101:15541-15544. CrossRef Medline

Kamigaki T, Fukushima T, Miyashita Y (2009) Cognitive set reconfiguration signaled by macaque posterior parietal neurons. Neuron 61:941-951. CrossRef Medline

Kimberg DY, Aguirre GK, D’Esposito M (2000) Modulation of task-related neural activity in task-switching: an fMRI study. Brain Res Cogn Brain Res 10:189-196. CrossRef Medline

Kolster H, Mandeville JB, Arsenault JT, Ekstrom LB, Wald LL, Vanduffel W (2009) Visual field map clusters in macaque extrastriate visual cortex. J Neurosci 29:7031-7039. CrossRef Medline

Konishi S, Nakajima K, Uchida I, Kikyo H, Kameyama M, Miyashita Y (1999) Common inhibitory mechanism in human inferior prefrontal cortex revealed by event-related functional MRI. Brain 122:981-991. CrossRef Medline

Koyama M, Hasegawa I, Osada T, Adachi Y, Nakahara K, Miyashita Y (2004) Functional magnetic resonance imaging of macaque monkeys performing visually guided saccade tasks: comparison of cortical eye fields with humans. Neuron 41:795-807. CrossRef Medline

Liston C, Matalon S, Hare TA, Davidson MC, Casey BJ (2006) Anterior cingulate and posterior parietal cortices are sensitive to dissociable forms of conflict in a task-switching paradigm. Neuron 50:643-653. CrossRef Medline

Miller EK, Cohen JD (2001) An integrative theory of prefrontal cortex function. Annu Rev Neurosci 24:167-202. CrossRef Medline

Monsell S (2003) Task switching. Trends Cogn Sci 7:134-140. CrossRef Medline

Moore T, Armstrong KM (2003) Selective gating of visual signals by microstimulation of frontal cortex. Nature 421:370-373. CrossRef Medline

Nakahara K, Hayashi T, Konishi S, Miyashita Y (2002) Functional MRI of macaque monkeys performing a cognitive set-shifting task. Science 295: 1532-1536. CrossRef Medline

Nakamura K, Roesch MR, Olson CR (2005) Neuronal activity in macaque SEF and ACC during performance of tasks involving conflict. J Neurophysiol 93:884-908. CrossRef Medline

Nobre AC, Gitelman DR, Dias EC, Mesulam MM (2000) Covert visual spatial orienting and saccades: overlapping neural systems. Neuroimage 11: 210-216. CrossRef Medline

Paus T, Castro-Alamancos MA, Petrides M (2001) Cortico-cortical connectivity of the human mid-dorsolateral frontal cortex and its modulation by repetitive transcranial magnetic stimulation. Eur J Neurosci 14:14051411. CrossRef Medline

Pouget P, Logan GD, Palmeri TJ, Boucher L, Paré M, Schall JD (2011) Neural basis of adaptive response time adjustment during saccade countermanding. J Neurosci 31:12604-12612. CrossRef Medline

Premereur E, Janssen P, Vanduffel W (2015a) Effector specificity in macaque frontal and parietal cortex. J Neurosci 35:3446-3459. CrossRef Medline

Premereur E, Van Dromme IC, Romero MC, Vanduffel W, Janssen P (2015b) Effective connectivity of depth-structure-selective patches in the lateral bank of the macaque intraparietal sulcus. PLoS Biol 13:e1002072. CrossRef Medline

Raichle ME, MacLeod AM, Snyder AZ, Powers WJ, Gusnard DA, Shulman GL (2001) A default mode of brain function. Proc Natl Acad Sci U S A 98:676-682. CrossRef Medline

Rizzolatti G, Riggio L, Dascola I, Umiltá C (1987) Reorienting attention across the horizontal and vertical meridians: evidence in favor of a premotor theory of attention. Neuropsychologia 25:31-40. CrossRef Medline

Rudebeck PH, Saunders RC, Prescott AT, Chau LS, Murray EA (2013) Prefrontal mechanisms of behavioral flexibility, emotion regulation and value updating. Nat Neurosci 16:1140-1145. CrossRef Medline

Rudebeck PH, Saunders RC, Lundgren DA, Murray EA (2017) Specialized representations of value in the orbital and ventrolateral prefrontal cortex: desirability versus availability of outcomes. Neuron 95:1208-1220.e5. CrossRef Medline

Rushworth MF, Hadland KA, Paus T, Sipila PK (2002) Role of the human medial frontal cortex in task switching: a combined fMRI and TMS study. J Neurophysiol 87:2577-2592. CrossRef Medline

Rushworth MF, Hadland KA, Gaffan D, Passingham RE (2003) The effect of cingulate cortex lesions on task switching and working memory. J Cogn Neurosci 15:338-353. CrossRef Medline

Schall JD, Hanes DP, Thompson KG, King DJ (1995) Saccade target selection in frontal eye field of macaque. I. Visual and premovement activation. J Neurosci 15:6905-6918. CrossRef Medline

Schrouff J, Rosa MJ, Rondina JM, Marquand AF, Chu C, Ashburner J, Phillips C, Richiardi J, Mourão-Miranda J (2013) PRoNTo: pattern recognition for neuroimaging toolbox. Neuroinformatics 11:319-337. CrossRef Medline

Shima K, Tanji J (1998) Role for cingulate motor area cells in voluntary movement selection based on reward. Science 282:1335-1338. CrossRef Medline

Sohn MH, Anderson JR (2001) Task preparation and task repetition: twocomponent model of task switching. J Exp Psychol Gen 130:764-778. CrossRef Medline

Sohn MH, Ursu S, Anderson JR, Stenger VA, Carter CS (2000) The role of prefrontal cortex and posterior parietal cortex in task switching. Proc Natl Acad Sci U S A 97:13448-13453. CrossRef Medline

Stoet G, Snyder LH (2003) Executive control and task-switching in monkeys. Neuropsychologia 41:1357-1364. CrossRef Medline

Van Dromme IC, Premereur E, Verhoef BE, Vanduffel W, Janssen P (2016) Posterior Parietal Cortex Drives Inferotemporal Activations During ThreeDimensional Object Vision. PLoS Biol 14:e1002445. CrossRef Medline

Vanduffel W, Fize D, Mandeville JB, Nelissen K, Van Hecke P, Rosen BR, Tootell RB, Orban GA (2001) Visual motion processing investigated us- 
ing contrast agent-enhanced fMRI in awake behaving monkeys. Neuron 32:565-577. CrossRef Medline

Vanduffel W, Zhu Q, Orban GA (2014) Monkey cortex through fMRI glasses. Neuron 83:533-550. CrossRef Medline

Wang Y, Matsuzaka Y, Shima K, Tanji J (2004) Cingulate cortical cells projecting to monkey frontal eye field and primary motor cortex. Neuroreport 15:1559-1563. CrossRef Medline

Wardak C, Ibos G, Duhamel JR, Olivier E (2006) Contribution of the monkey frontal eye field to covert visual attention. J Neurosci 26:4228-4235. CrossRef Medline

Wardak C, Olivier E, Duhamel JR (2011) The relationship between spatial attention and saccades in the frontoparietal network of the monkey. Eur J Neurosci 33:1973-1981. CrossRef Medline
Woodward TS, Ruff CC, Ngan ET (2006) Short- and long-term changes in anterior cingulate activation during resolution of task-set competition. Brain Res 1068:161-169. CrossRef Medline

Wylie GR, Javitt DC, Foxe JJ (2004) Don't think of a white bear: an fMRI investigation of the effects of sequential instructional sets on cortical activity in a task-switching paradigm. Hum Brain Mapp 21:279-297. CrossRef Medline

Yeung N, Monsell S (2003a) Switching between tasks of unequal familiarity: the role of stimulus-attribute and response-set selection. J Exp Psychol Hum Percept Perform 29:455-469. CrossRef Medline

Yeung N, Monsell S (2003b) The effects of recent practice on task switching. J Exp Psychol Hum Percept Perform 29:919-936. CrossRef Medline 